\title{
HETEROKARYON COMPATIBILITY OF CLOSELY RELATED WILD ISOLATES OF ASPERGILLUS NIDULANS
}

\author{
M. GRINDLE \\ A.R.C. Unit of Biometrical Genetics, Department of Genetics, \\ University of Birmingham
}

Received 1.iii.63

\section{INTRODUCTION}

IT was shown in an earlier report (Grindle, I963, that wild isolates of $A$. nidulans formed heterokaryons readily with their own respective spore-colour mutants but they rarely formed heterokaryons with the spore-colour mutants derived from a different wild isolate of the same species. The compatible isolates, that is those that did form inter-strain heterokaryons, were very similar in morphology and had been obtained in the wild from localities less than one mile apart. It seemed, therefore, as if the ability to form inter-strain heterokaryons might be restricted to isolates obtained within a limited area and closely related genetically. To test this possibility, an additional 18 wild isolates of $A$. nidulans were sampled from different areas in England. This paper describes the intra- and inter-strain compatibility of these isolates.

\section{MATERIALS AND METHODS}

The wild isolates were recovered from two localities, Birmingham and Beamish (County Durham), which are 200 miles apart. Small quantities of surface soil or fruiting bodies of various Basidiomycete fungi were sampled from these localities over areas of 8 square miles and $\mathrm{x}$ square mile respectively.

The fruiting bodies were placed in sterile Petri dishes and after 24 hours any spores that had collected in the dishes were suspended in a dilute solution of Tween 80 (a wetting agent). Soil samples were shaken in sterile capped tubes containing Tween 80 and allowed to stand until only the very fine soil particles remained in suspension. Small amounts of the resultant spore suspensions were plated undiluted on Plunkett's medium (PM) of about $p \mathrm{H} 4^{\circ} \circ$ and on $\mathrm{PM}$ of $p \mathrm{H} 5^{\circ} \circ$ containing 4 per cent. sodium chloride and incubated at $25^{\circ} \mathrm{C}$. Soil particles were also sprinkled directly on to both these media. Since colonies of $A$. nidulans grow rapidly and sporulate profusely on PM, they could be distinguished readily and isolated on to fresh media after only four days. When the suspension contained a heavy bacterial inoculum, Czapek minimal medium (MM) containing 5 per cent. sodium chloride proved to be a much better selective medium for $A$. nidulans and also for many other species of this genus.

All isolates recovered from the same spore suspension were transferred on to plates of MM where they were compared subjectively after several days' growth. If a number of morphologically identical colonies was obtained, only one of them was selected at random for testing. Two or more isolates recovered from the same source were selected only if they were quite different in appearance, with one exception, namely isolates 34 and 35 which were phenotypically indistinguishable.

The techniques used to evaluate the morphological characteristics and heterokaryon compatibility of the selected isolates are those described previously (Grindle, 1963). 


\section{RESULTS}

As the wild isolates (listed in table $\mathrm{I}$ ) and their spore-colour mutants became available, they were inoculated together, in various combinations, on PM ( $\left.p \mathrm{H}_{5} \cdot 2\right)$ and on 2 per cent. malt agar ( $\left.p \mathrm{H}_{5} .5\right)$. After six days' growth, each mixed culture was examined at Ioo $\times$ magnification for the presence of heterokaryotic conidial heads. The frequencies of heterokaryotic conidial heads observed in the various combinations are given in table 2.

TABLE I

List of isolates

\begin{tabular}{|c|c|c|c|c|c|}
\hline \multirow{2}{*}{$\begin{array}{c}\text { Isolate } \\
\text { No. }\end{array}$} & \multicolumn{4}{|c|}{ Isolation source } & \multirow{2}{*}{$\begin{array}{l}\text { Date of } \\
\text { isolation }\end{array}$} \\
\hline & Local & & & & \\
\hline $\begin{array}{l}2 \\
26 \\
27 \\
28 \\
29 \\
31 \\
33 \\
34 \\
35 \\
36 \\
37\end{array}$ & $\begin{array}{c}\text { BIRMINGHAM } \\
\text { ", } \\
\text { ", } \\
\text { ", } \\
\text { ", } \\
\text { ", } \\
\text { ", }\end{array}$ & $\begin{array}{l}A \\
B \\
B \\
C \\
D \\
E \\
E \\
E \\
F \\
F\end{array}$ & $\begin{array}{c}\text { Airborne } \\
\text { Collybia velutipes } \\
\text { ", } \\
\text { ", } \\
\text { Polyporus sp. } \\
\text { Collybia velutipes } \\
\text { ", } \\
\text { ", } \\
\text { ", }\end{array}$ & $\begin{array}{c}\text { Park } \\
\text { Woodland } \\
\text { ", } \\
\text { ", } \\
\text { Golf course } \\
\text {," } \\
\text { ", } \\
\text { Garden } \\
\text {," }\end{array}$ & $\begin{array}{c}1954 \\
\text { Dec. I } 961 \\
\text { Mar. I } 962 \\
\text { April" } 1962 \\
\text { ", } \\
\text { ", } \\
\text { May }{ }^{\prime} 962 \\
\text {," }\end{array}$ \\
\hline $\begin{array}{l}38 \\
40 \\
42 \\
43 \\
44 \\
45 \\
46\end{array}$ & $\begin{array}{c}\text { BEAMISH } \\
\text {," } \\
\text { ", } \\
\text { ", } \\
\text { ", }\end{array}$ & $\begin{array}{l}\text { A } \\
\text { B } \\
\text { C } \\
\text { D } \\
\text { D } \\
\text { E } \\
\text { E }\end{array}$ & $\begin{array}{c}\text { Soil } \\
\text { ", } \\
\text { ", } \\
\text { ", } \\
\text { ", }\end{array}$ & $\begin{array}{c}\text { Garden } \\
\text { Pasture } \\
\text { Woodland } \\
\text {," } \\
\text { ", } \\
\text { ", }\end{array}$ & $\begin{array}{c}\text { June } 1962 \\
\text { ", } \\
\text { ", } \\
\text { ", } \\
\text { ", }\end{array}$ \\
\hline
\end{tabular}

The letters are used to distinguish between different isolation sources; isolates obtained from identicaily lettered regions, e.g. 27 and 28 , or 43 and 44 , were recovered from the same fruiting body or the same soil sample.

After testing several of the isolates, it became clear that they could be divided into distinct compatibility groups and that the behaviour of any isolate in a particular group was representative of all other isolates in that same group. For example, if isolates $\mathrm{X}, \mathrm{Y}$ and $\mathrm{Z}$ were equally compatible with any of the spore-colour mutants derived from them (i.e. about 4 per cent. of the conidial heads in any combination of strains were heterokaryotic), any new isolate which formed heterokaryons readily with $\mathrm{X}$ would also form heterokaryons, just as readily, with $Y$ and $Z$. Because of this, some isolates were tested in very few combinations, sufficient only to place them in a particular compatibility group. These will be referred to as $h-c$ (heterokaryoncompatibility) groups. 
After completing the heterokaryon tests, all the wild isolates were grown simultaneously at $25^{\circ} \mathrm{C}$. on $\mathrm{MM}$ containing New Zealand agar and their morphological characteristics were evaluated. The characters measured and the data obtained are given in table 3 . Representative isolates are illustrated in plates I and II.

TABLE 2

Frequencies of mixed conidial heads in intra* and inter-strain combinations. The frequencies are estimated by examining several areas of each mixed culture in which both green-spored and while- (or yellow-) spored conidiophores are present and intermingled: the number of mixed (i.e. heterokariotic) conidial heads-those with both green and coloured spores-is given as a percentage of the total conidial heads examined.

Spore-colour mutants

\begin{tabular}{|c|c|c|c|c|c|c|c|c|c|c|c|c|c|c|c|c|c|c|}
\hline & $2 w$ & $28 w$ & $29 y$ & $3^{8 w}$ & $42^{*}$ & $44 y$ & $45 w$ & $4^{6 y}$ & $26 y$ & $27 y$ & $3^{6 w}$ & 3ry & $33 w$ & $37 \mathrm{y}$ & $34 w$ & $35 y$ & 4ow & $43 y$ \\
\hline 2 & $3 \cdot 4^{14}$ & $-48^{3}$ & $3.5^{3}$ & $\ldots$ & $\ldots$ & $\ldots$ & $\ldots$ & $\ldots$ & $\ldots$ & 0 & 0 & o & o & $\ldots$ & 0 & 0 & $\ldots$ & $\ldots$ \\
\hline 28 & $4^{\cdot 8^{4}}$ & $4 \cdot 9=$ & $40^{3}$ & $45^{4}$ & $\ldots$ & $\ldots$ & $3.0^{4}$ & $\ldots$ & 0.24 & $0.1^{3}$ & 0 & o & o & $\ldots$ & o & o & $\ldots$ & $\ldots$ \\
\hline 29 & $3.7^{3}$ & $3.7^{3}$ & $4 \cdot 7=8$ & $3.2:$ & $\ldots$ & $\ldots$ & 2.84 & $3^{2} 2^{4}$ & $0.01^{3}$ & $\mathrm{O}^{\circ} \mathrm{O}^{4}$ & 0 & o & o & o & o & o & o & o \\
\hline $3^{8}$ & $\ldots$ & 3.84 & $2.4^{4}$ & $4 \cdot 8 \div 11$ & $\ldots$ & $\ldots$ & $\ldots$ & $\ldots$ & 0 & $\ldots$ & $\ldots$ & $\ldots$ & 0 & $\ldots$ & $\ldots$ & 0 & 0 & o \\
\hline $4^{2}$ & $\ldots$ & $\ldots$ & $\ldots$ & $6 \cdot 0^{4}$ & $\ldots$ & $\ldots$ & $\ldots$ & $\ldots$ & $\ldots$ & $\ldots$ & $\ldots$ & $\cdots$ & $\ldots$ & $\cdots$ & $\ldots$ & $\ldots$ & $\ldots$ & $\ldots$ \\
\hline 44 & $\ldots$ & $\ldots$ & $\ldots$ & $\ldots$ & $\cdots$ & $5 \cdot 3^{8}$ & $3 \cdot 4^{4}$ & $4.3^{4}$ & $\cdots$ & $\ldots$ & $\ldots$ & $\cdots$ & $\cdots$ & $\cdots$ & $\ldots$ & $\cdots$ & o & o \\
\hline 45 & $\cdots$ & $3^{2} 2^{3}$ & $3.2^{4}$ & $\ldots$ & $\ldots$ & $4 \cdot 3^{3}$ & $3 \cdot 7^{13}$ & $4 \cdot 3^{4}$ & 0 & $\cdots$ & $\ldots$ & $\cdots$ & $\cdots$ & $\cdots$ & $\cdots$ & $\cdots$ & $\cdots$ & o \\
\hline $4^{6}$ & $\ldots$ & $\ldots$ & $3^{6} 6^{4}$ & $\ldots$ & $\ldots$ & $4.5^{+}$ & $4^{.2}{ }^{3}$ & $3.6^{7}$ & $\ldots$ & $\ldots$ & $\ldots$ & $\ldots$ & $\ldots$ & $\cdots$ & $\ldots$ & $\ldots$ & $\ldots$ & 0 \\
\hline 26 & $\ldots$ & 0.24 & 0 & 0 & $\ldots$ & $\ldots$ & 0 & 0 & $2 \cdot 7^{34}$ & 2.6 & 4.14 & 0 & o & o & $0.01{ }^{4}$ & 0.14 & 0 & o \\
\hline 27 & 0 & 0 & 0 & $\ldots$ & $\ldots$ & $\cdots$ & $\cdots$ & $\ldots$ & $3.0^{4}$ & $3.4^{16}$ & $\ldots$ & o & 0 & $\ldots$ & $0.0 t^{4}$ & $\ldots$ & $\ldots$ & $\ldots$ \\
\hline $3^{6}$ & 0 & $\ldots$ & 0 & $\ldots$ & $\ldots$ & $\ldots$ & $\ldots$ & $\ldots$ & $4.0^{4}$ & $\ldots$ & $3.5^{13}$ & 0 & $\cdots$ & $\ldots$ & o & $\cdots$ & $\ldots$ & $\cdots$ \\
\hline 31 & 0 & $\cdots$ & 0 & $\ldots$ & $\ldots$ & $\cdots$ & $\cdots$ & $\ldots$ & 0.034 & $\ldots$ & $\cdots$ & $4^{8^{14}}$ & $3^{2} 2^{3}$ & $2 \cdot 9^{3}$ & o & o & $\ldots$ & $\ldots$ \\
\hline 33 & 0 & $0.3+$ & 0 & 0 & $\ldots$ & $\ldots$ & $\ldots$ & $\cdots$ & 0 & 0 & 0 & $3.3^{3}$ & $5 \cdot 0 " 1$ & $2.7^{3}$ & 0 & 0 & o & 0 \\
\hline 37 & $\ldots$ & $\ldots$ & o & $\ldots$ & $\ldots$ & $\ldots$ & $\ldots$ & $\ldots$ & 0 & $\cdots$ & $\ldots$ & 3.14 & 2.54 & $4 \cdot 3^{19}$ & 0 & $\ldots$ & $\ldots$ & $\cdots$ \\
\hline 34 & o & o & 0 & $\ldots$ & $\ldots$ & $\ldots$ & $\ldots$ & $\ldots$ & 0.064 & $0.07^{4}$ & 0 & 0 & 0 & 0 & $4.0^{30}$ & $3.8^{4}$ & o & o \\
\hline 35 & o & o & 0 & $\ldots$ & $\ldots$ & $\ldots$ & $\ldots$ & $\ldots$ & $0.07^{4}$ & $0.04^{4}$ & 0 & o & $\ldots$ & 0 & $3.4^{4}$ & $3.8=$ & 0 & $\ldots$ \\
\hline 40 & $\ldots$ & $\ldots$ & $\cdots$ & 0 & $\cdots$ & 0 & $\ldots$ & $\ldots$ & $\circ$ & $\ldots$ & $\cdots$ & o & 0 & $\cdots$ & o & $\ldots$ & $21^{16}$ & $3.3^{4}$ \\
\hline 43 & $\ldots$ & $\ldots$ & o & 0 & $\ldots$ & o & 0 & 0 & o & $\ldots$ & $\ldots$ & $\ldots$ & o & $\cdots$ & o & $\ldots$ & $1.4^{4}$ & 3.831 \\
\hline
\end{tabular}

(Superscripts denote number of replicate tests on which frequencies are based; $w=$ white, $y=$ yellow.) Combinations denoted by a ... sign have not been tested. A zero score indirates that each of the 3 or 4 replicate tests of that combination failed to produce a single mixed conidial head.

* No spore-colour mutant was derived from this isolate.

By combining the information from tables I, 2 and 3 , and by relating the heterokaryon compatibility of the isolates to their morphological characteristics and their isolation source (table 4), the following points emerge.

I. Wild isolates of $A$. nidulans can be differentiated on the basis of their ability to form heterokaryons with each other into a number of distinct groups.

2. Isolates within a particular $h-c$ group form heterokaryons with their own spore-colour mutants with about the same frequency as they do with those derived from any other isolate in that group. About 4 per cent. of the conidial heads formed by a mixed culture consisting of any two different strains are heterokaryotic. 


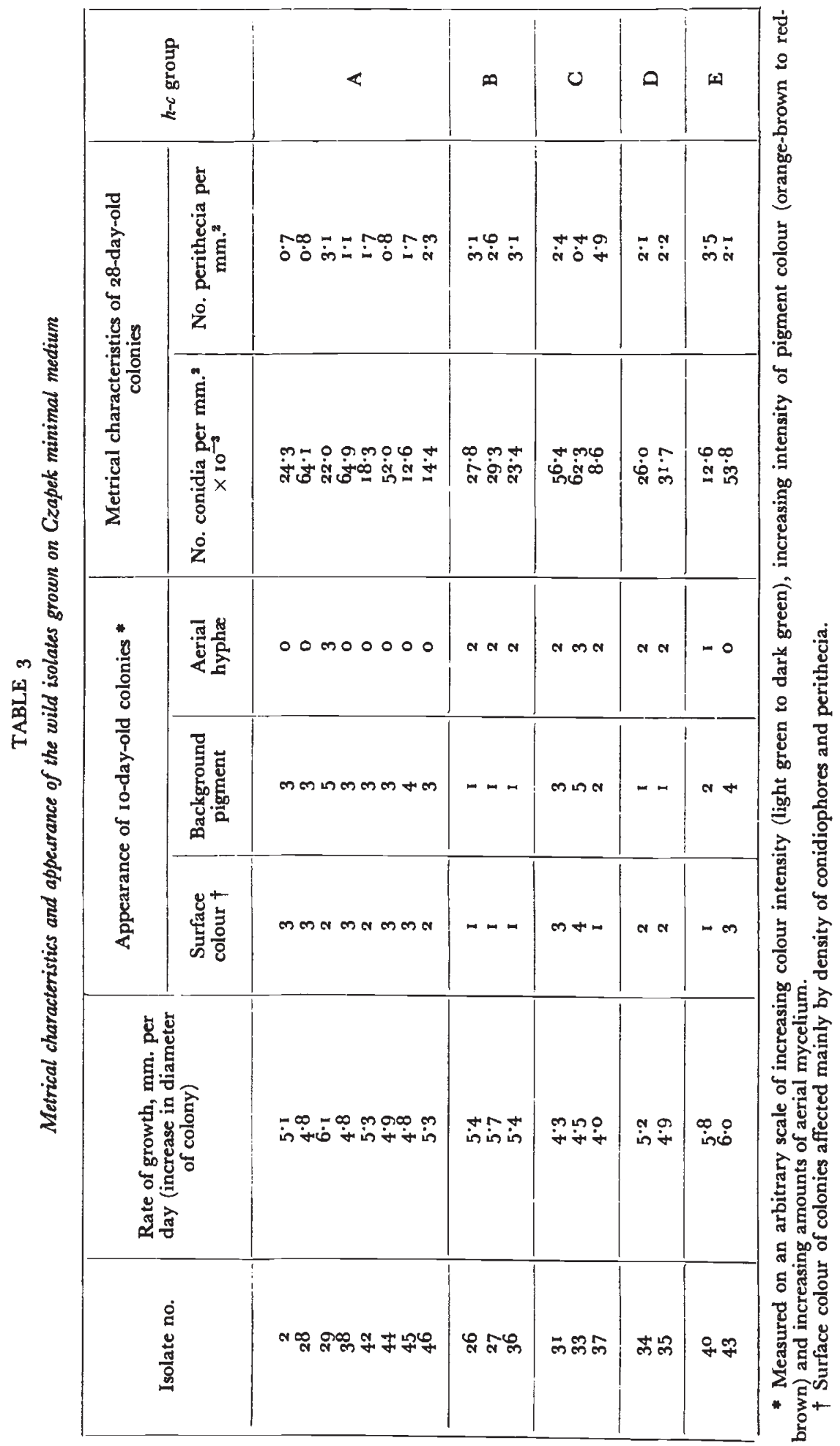


3. Isolates of different $h-c$ groups are either incompatible or they form heterokaryons very rarely, only about 0.1 per cent. of the conidiophores produced by mixed cultures being heterokaryotic.

\section{TABLE 4}

Comparisons of wild isolates in relation to their heterokaryon compatibility

\begin{tabular}{|c|c|c|c|}
\hline $\begin{array}{c}h-c \\
\text { group }\end{array}$ & $\begin{array}{c}\text { Isolate } \\
\text { No. }\end{array}$ & $\begin{array}{c}\text { Isolation } \\
\text { source }\end{array}$ & Special features \\
\hline & 2 & Birmingham & \\
28 &, & Same as 2 except that sporulation more profuse. \\
& 29 & Quite different from all other isolates in this group \\
particularly in rate of growth and sexuality. \\
A
\end{tabular}

All isolates except 29 almost identical in appearance and in rate of growth.

\begin{tabular}{c|c|c|c}
\hline & & & \\
B & 26 & Birmingham & \\
& 27 &, & Same as 26. \\
& 36 &, & Same as 26.
\end{tabular}

All isolates identical in appearance and have same rates of growth. Isolates in this group bear a slight resemblance to those of group D.

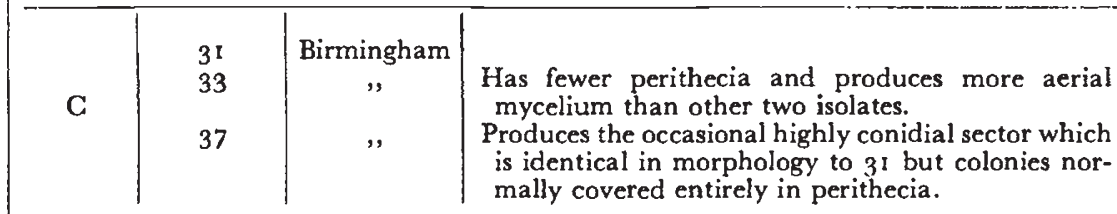

All isolates are different in appearance but have similar rates of growth. Isolates in this group quite different from those of all other groups.

\begin{tabular}{l|l|l|l}
\hline $\mathrm{D}$ & 34 & Birmingham & \\
& 35 &,, & Same as 34.
\end{tabular}

Both isolates identical in all respects. They bear a slight resemblance to isolates of group B.

\begin{tabular}{c|c|c|c}
\hline E & Beamish & $\begin{array}{c}\text { Produces the occasional highly conidial sector which } \\
\text { is identical in morphology to 43 but colonies are } \\
\text { normally very pale green in appearance and have } \\
\text { few conidiophores. }\end{array}$ \\
43 &,, &
\end{tabular}

Both isolates different in appearance but have same rates of growth. Isolate 43 bears slight resemblance to some isolates in group $\mathrm{A}$.

4. Isolates of the same $h-c$ group tend to be either identical or extremely similar in appearance. The variation in surface morphology and in growth rate (but not in conidial density or sexuality) among isolates of the same group is much less than the variation among 
isolates of different groups (table 5). Sporulation and sexuality, however, are not satisfactory indicators of naturally occurring nuclear differences (see section 4).

5. Different isolates obtained from the same locality, even from the same soil sample, may be incompatible.

TABLE 5

Analysis of variance of rates of growth and conidial density of the wild isolates

\begin{tabular}{|c|c|c|c|c|c|c|c|c|}
\hline \multirow{2}{*}{ Source of variation } & \multicolumn{4}{|c|}{ Rate of growth } & \multicolumn{4}{|c|}{ Conidial density } \\
\hline & $\mathrm{N}$ & MS & VR & $\mathbf{P}$ & $\mathrm{N}$ & MS & VR & $P$ \\
\hline Between $h$-c groups . & 4 & 0.963 & 7.70 & $0.01-0.001$ & 4 & 104.72 & $\ldots$ & $\ldots$ \\
\hline Within $h-c$ groups & r 3 & 0.125 & $\ldots$ & $\ldots$ & I3 & $471 \cdot 52$ & $\ldots$ & $\ldots$ \\
\hline
\end{tabular}

6. Wild isolates obtained from different, widely-separated localities may be compatible and very similar in surface morphology.

7. Wild isolates of one compatibility group ( $h$-c group A) are much more common than isolates of any other group.

\section{DISCUSSION}

\section{(i) The significance of heterokaryon compatibility for outbreeding}

Heterokaryosis, the occurrence of genetically different nuclei within a common cytoplasm, is an essential preliminary to outcrossing in homothallic fungi (see Buxton, I96o, for review). In species such as A. nidulans, the nuclei from different parental strains can be brought together in the same cell lineage only if those strains are heterokaryon compatible. Consequently, their ability to form heterokaryons with each other determines whether they can exchange genetic material.

It is evident from our data that many combinations of isolates are incompatible. Therefore, no interchange of genetic material can occur and the isolates cannot interbreed. Where several isolates are compatible, and can share a common gene pool, it seems likely that the various nuclear types differ so little genetically that the consequences of meiotic or mitotic recombination within many heterokaryons would be little different from those of selfing. As pointed out previously (Grindle, 1963), however, some inter-strain heterokaryons may occur so infrequently that they will not be detected by our technique. Also, heavy selection pressures which favour heterokaryon formation may occur under certain conditions in nature. Furthermore, since the measurable characters of fungi are far fewer than those of higher plants, isolates that are apparently identical morphologically may perhaps differ by many genes. 
If two wild isolates that differ only in physiological characters are compatible, it is clear that new physiological races can arise as a consequence of genetic recombination within a heterokaryon formed by two apparently identical strains. Claims to have demonstrated this, however, are nearly always founded on laboratory studies in which the heterokaryons were formed between different artificially induced auxotrophic strains, and the presence of many mutations, especially those for nutritional requirements, may have increased the compatibility far above that of the wild homokaryotic isolates. Since the differences among wild isolates are quite unlike the differences among laboratory mutants, compatibility of wild isolates may bear little relation to the compatibility of laboratory mutants.

In many instances, evidence for heterokaryosis and mitotic recombination are based on studies in which heterokaryons were obtained between various mutant forms of a single wild isolate so that all the heterokaryons produced are intra-strain heterokaryons. Such data on genetic recombination gives little indication of what might be expected to occur under natural conditions.

It would seem that the significance of heterokaryosis for outbreeding in some fungi may be much less than has been thought. If natural inter-strain heterokaryons occur with a very low frequency, and especially if they usually involve homokaryons which are very similar in genotype, it is possible that the variation within some species of filamentous fungi, due to meiotic or mitotic recombination, may be less than the variation due to direct mutation.

\section{(ii) Genetic relationships of wild isolates}

Wild isolates of $A$. nidulans that can form heterokaryons with each other and can, therefore, interbreed are usually extremely similar in surface morphology. This suggests that two quite different criteria, heterokaryon compatibility and morphological similarity, may be alternative means of assessing the genetical relationships of different isolates. Many of our isolates which were not compatible, however, were nevertheless very similar in appearance. Conversely, a few of the isolates that were dissimilar in appearance were highly compatible (e.g. isolates 28 and 29) while others (e.g. 26 and 28) were compatible to a slight extent.

Obvious differences in phenotype do not necessarily imply large underlying differences in genotype, and morphologically distinct strains may differ by only a single nuclear gene. Indeed, the variation encountered may, in some cases, be due to cytoplasmic rather than nuclear gene differences. For example, two pairs of highly compatible isolates, $3 \mathrm{I}$ and 37, 40 and 43, each contained a high-sexual and lowsexual isolate. The high-sexual isolate of each pair (i.e. 37 and 40), however, produced occasional low-sexual sectors that were identical in all respects to the other compatible isolate (see plate II, fig. 3). Jinks (1956, I957) showed that it was possible to select for high- and 
low-sexual progeny from a single parental colony of Aspergillus glaucus and concluded that these differences in sexuality were transmitted in the cytoplasm and not by the nucleus. Similar selections for highand low-sexual lines of several Birmingham wild isolates of $A$. nidulans have been successful (Arlett, I96o; Jinks and Grindle, unpublished; Croft, 1963).

Thus, if we assess the genetical relationships of wild isolates from either their appearance or their compatibility we do not necessarily reach the same conclusions. The two criteria are complementary rather than alternatives. This is seldom considered, however, in fungal taxonomy and species relationships are usually decided entirely on phenotypic characters. By doing so, isolates which are similar in appearance but which cannot share a common gene pool will be classified as the same species.

If we classify our isolates of $A$. nidulans according to their ability to exchange genes freely with each other, each of our $h-c$ groups would become separate species or subspecies. Like the sibling species of Drosophila (see Patterson and Stone, 1952) these species units would comprise phenotypically similar but genetically isolated individuals. Whether such a system of classification can be applied satisfactorily to microorganisms must await further studies.

\section{SUMMARY}

Eighteen wild isolates of Aspergillus nidulans were obtained from two widely separated localities in England. Their morphological characteristics were compared and they were tested for their ability to form heterokaryons with each other. The results showed that:

I. The ease with which wild isolates form heterokaryons with each other varies greatly.

2. Many isolates, even if obtained from the same soil sample, are incompatible in that they do not form heterokaryons with each other.

3. Regardless of the locality from which they are recovered, highly compatible isolates are usually identical or extremely similar in surface morphology.

The significance of these findings for outbreeding of filamentous fungi and for the genetical relationships of wild isolates is discussed.

Acknowledgments.-I wish to thank Dr J. L. Jinks for advice and criticism during the preparation of this report, Miss M. Leighton and Mr K. B. Parry for assistance with the illustrations and Professor K. Mather for comments on the manuscript.

\section{REFERENCES}

ARLETT, C. F. 1960. A system of cytoplasmic variation in Aspergillus nidulans. Heredity, ${ }^{15}, 377-388$.

Buxton, E. w. 1960. Heterokaryosis, Saltation and Adaptation. In Plant Pathology,

Vol. 2. Edited by Horsfall, J. G., and Dimond, A. E. Academic Press. New

York. 
Plate II
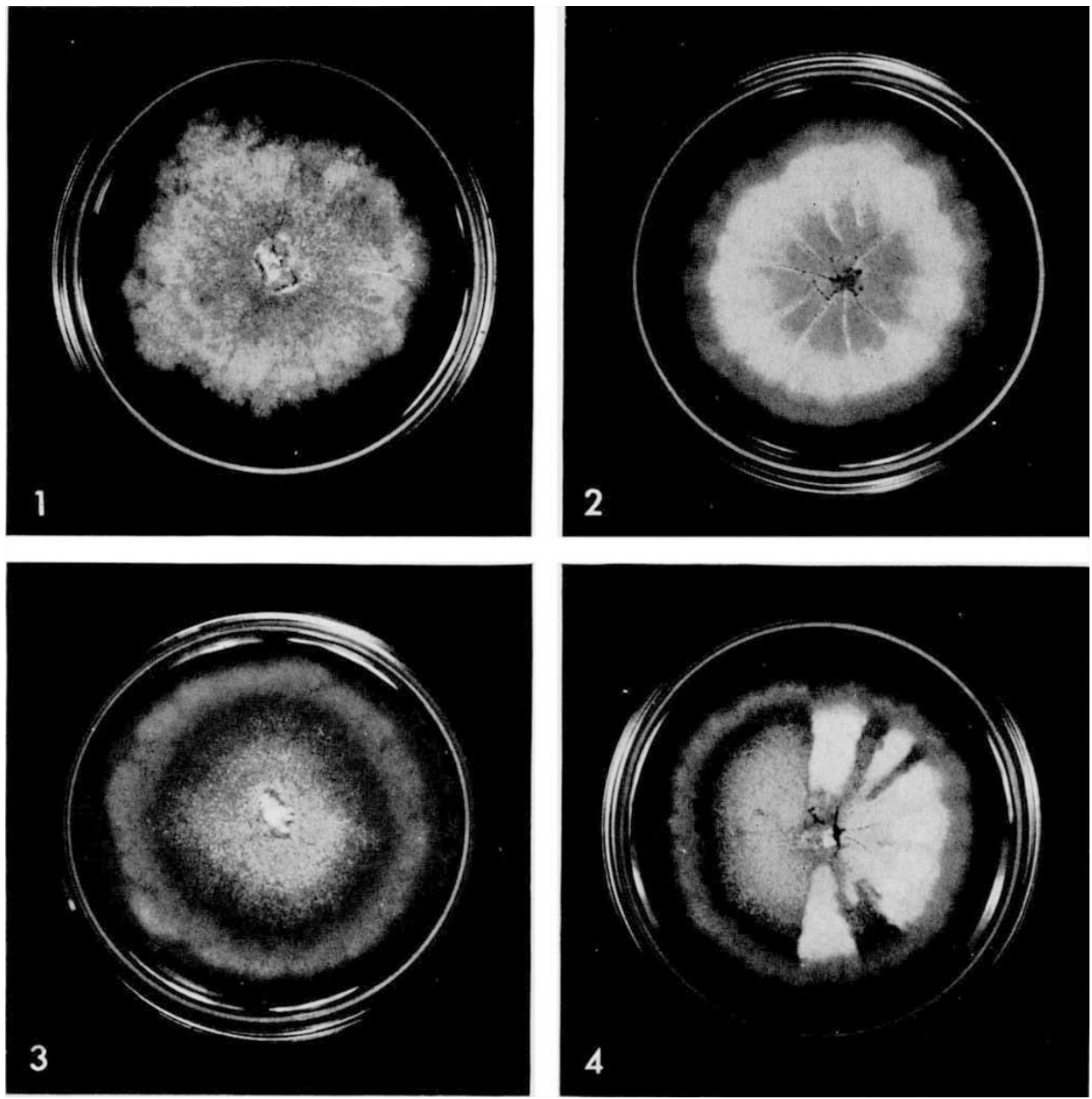

Fig. I.- Isolate 34, a typical member of $h-c$ group D, Note the slight resemblance, especially in surface colouration, to isolate 36 .

Figs. 2 and 3.--Isolates 40 and 43 , which are the high- and the low-sexual members respectively, of $h-c$ group E. Note the similarity between isolate 43 and the typical colony from $h-c$ group A (isolate 28 ).

FIg. 4.-A subculture of isolate 40 , showing the high-conidial sectors which resemble isolate 43 in appearance.

All colonies I I days old, growing on Czapek minimal medium. 

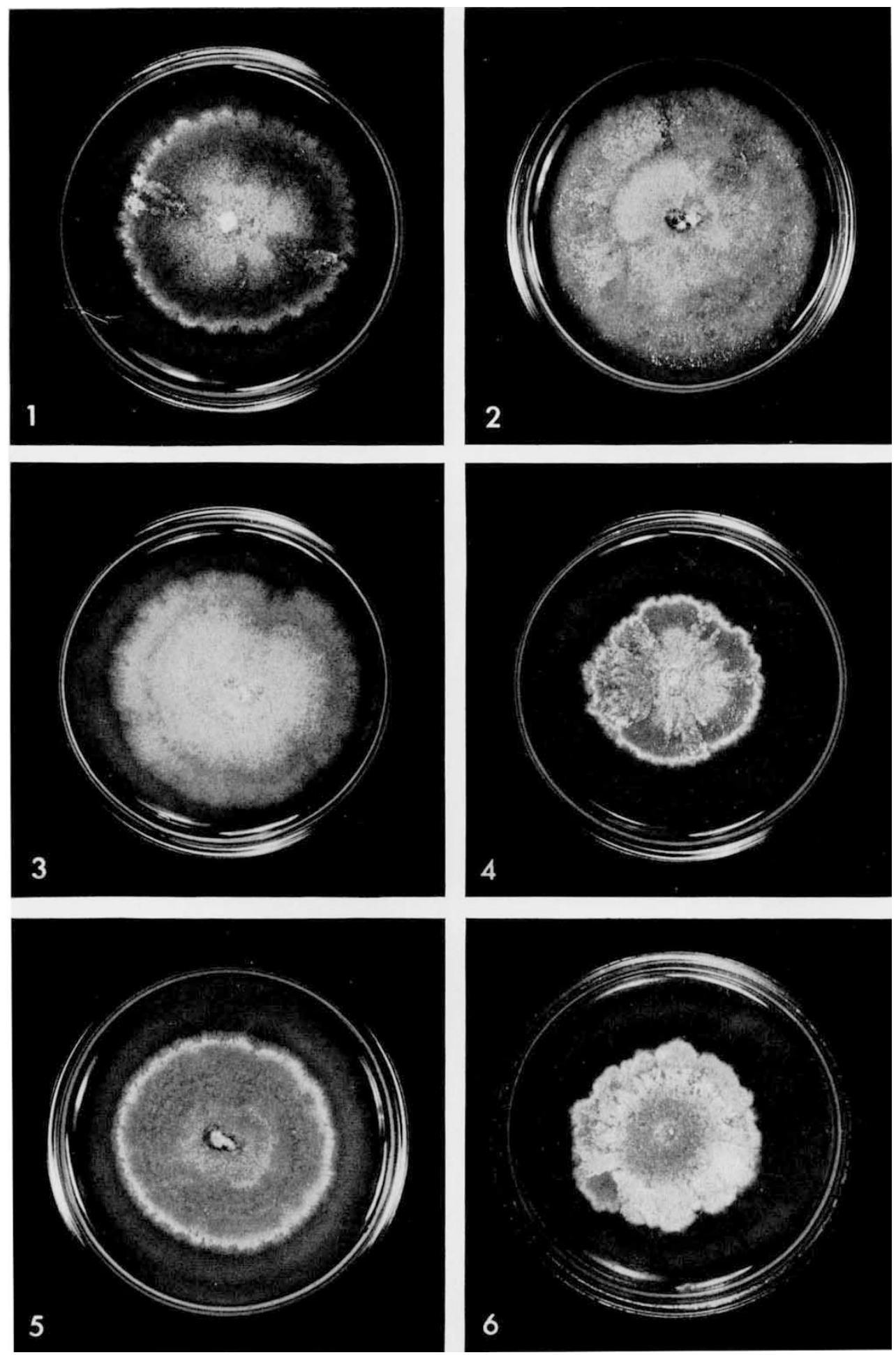

Frgs. I and 2.-Typical] (isolate 28) and atypical (isolate) members, respectively, of $h^{-c}$ group A.

Frg. 3.- Isolate 36 , a typical member of h-c group B.

Figs. 4-6.- Isolates 3 I, 33 and 37 , respectively, all in $h-c$ group C. Note that apart from differences in sexuality, isolates $3^{1}$ and 37 are very similar in appearance.

All colonies growing on Czapek minimal medium. Isolate 33 is 12 days old; all other colonies are I I days old. 
CROFT, J. H. I963. M.Sc. Thesis, University of Birmingham.

GRINDLE, M. 1963. Heterokaryon compatibility of unrelated strains in the Aspergillus nidulans group. Heredity, 18 , I91-204.

JINks, J. L. 1956. Naturally occurring cytoplasmic changes in fungi. C. R. Lab. Carlsberg, série physiologique, 26, 183-203.

JiNks, J. L. 1957. Selection for cytoplasmic differences. Proc. Roy. Soc. B, I46, 527-540.

patTeRSON, J. T., AND STONE, W. S. 1952. Sibling species and chromosome races. In Evolution in the genus Drosophila. Macmillan Book Company. New York.

\section{NOTE ADDED IN PROOF}

Burnett and Boulter (New Phytol. 62, $217-236$, 1963) have found that their wild isolates of the heterothallic fungus Mycocalia denudata can be placed in two groups between which there seems to be a complete sterility barrier. They suggest that these groups may be comparable to sibling species. 